\title{
FOTOGRAFÍA Y COMERCIO FOTOGRÁFICO EN COPIAPÓ (1909-1952). EL ESTUDIO FOTOGRÁFICO DE JOSÉ ANTONIO OLIVARES VALDIVIA
}

\author{
PHOTOGRAPHY AND PHOTOGRAPHIC TRADE IN COPIAPÓ (1909-1952). \\ THE PHOTOGRAPHIC STUDY OF JOSE ANTONIO OLIVARES VALDIVIA
}

\author{
Samuel Salgado Tello*
}

\begin{abstract}
El siguiente artículo tiene como objetivo describir las principales características que la práctica fotográfica tuvo en la ciudad de Copiapó entre 1910 y 1948. Siguiendo este planteamiento, fue investigado la trayectoria comercial y cultural del estudio fotográfico de José Antonio Olivares Valdivia, nacido en Ovalle en 1884 y fallecido en Copiapó en 1948. El comienzo de esta investigación se encuentra en el trabajo de preservación del Archivo Fotográfico del Museo Regional de Atacama, donde se desarrollaron dos áreas de trabajo. La metodología de trabajo contextualizó la producción fotográfica del período y la posibilidad de construir una biografía comercial de José Antonio Olivares Valdivia. Durante este trabajo se revisaron los periódicos de las ciudades de Ovalle y Copiapó. En sus páginas se encontraron diversos avisos comerciales, los que fueron vinculados con el trabajo del fotógrafo. Esto nos mostró una forma de aproximación a la fotografía que, por falta de otras investigaciones, puede parecer hoy singular, pero no cabe duda que fue practicada también por otros fotógrafos del período.
\end{abstract}

Palabras claves: Fotografía, fotografía de estudio, retrato, retrato fotográfico, comercio, Copiapó.

The following article aims to describe the main features photographic practice was in the city of Copiapó between 1910 and 1948. Following this approach was investigated commercial and cultural background of the photo studio of José Antonio Olivares Valdivia, born in Ovalle 1884 and died in Copiapó 1948. the beginning of this research is in the work of preserving the Photographic Archive of Regional Museum of Atacama, where two work areas were developed. The methodology, contextualize the photographic production of the period and the possibility of building a business biography of Jose Antonio Olivares Valdivia. During this work, the newspapers of the cities of Ovalle and Copiapó were reviewed. In its page's various commercial ads were found which were linked to the photographer's work. This showed us a way of approaching photography, for lack of other research, may seem unusual today, but no doubt it was also practiced by other photographers of the period.

Key words: Photography, studio photography, portrait, portrait photography, trade, Copiapó.

\section{Introducción}

\section{Los desconocidos fotógrafos de provincia}

Entre 1900 y 1950 en Chile se han identificado 1.763 fotógrafos. Las prácticas de los fotógrafos y fotógrafas eran diversas, pero se han reconocido como mayoritarias las siguientes: fotógrafos de estudio, reporteros gráficos, camarógrafos, minuteros, aficionados. En el norte de chile, entre esos años, el total de fotógrafos era de 144 y en la región de Atacama se identificaron 24, la mayoría de ellos trabajando como fotógrafos de estudio (Rodríguez 2011: 437-459).

José Antonio Olivares Valdivia nació en la ciudad de Ovalle el 4 de mayo de 1884. Fue el hijo mayor del matrimonio formado por Reinaldo Olivares y Nicolasa Valdivia. Al parecer, el matrimonio no pasaba por una buena situación económica, lo que los obligó a buscar trabajo en otra ciudad más próspera del norte del país. Eligieron la ciudad de Antofagasta. A su hijo, en ese momento de cinco años, lo dejaron al cuidado de un tío, Antonio Valdivia, un comerciante de la ciudad. Olivares Valdivia, desde muy pequeño, trabajó para él en los negocios de Ovalle ${ }^{1}$.

En la ciudad de Ovalle, entre 1903 y 1914, trabajaban tres fotógrafos: José B. Álvarez, quien hacia 1906 se identificaba como el único fotógrafo de la ciudad, Carlos S. Martín y Enrique Cood (Rodríguez 2011: 40, 106, 243), cada uno con un estudio fotográfico. Pero, además, visitaban la ciudad fotógrafos ambulantes que se presentaban por la prensa con avisos que destacaban las últimas novedades en retratos y los precios más convenientes. En 1892 la Fotografía Europea, que estaba formada

* Centro Nacional del Patrimonio Fotográfico, Universidad Diego Portales, Santiago, Chile. Correo electrónico: samuel. salgado@udp.cl 
por los "afamados fotógrafos señores Pellandino y Napoleone", quienes avisaban que llegaban a la ciudad en el tren del lunes y "que viene aquí con el objetivo de establecer su fotografía, por un corto tiempo. Se nos informa que estos señores traen para sus trabajos una poderosa máquina del último sistema, en la que ejecutan primorosos trabajos de todas formas y tamaños, siendo sus precios relativamente baratos. Establecerán su taller en el Hotel de France, Plaza de Armas"2.

En la ciudad de Copiapó, el comercio fotográfico presentaba ciertas similitudes con Ovalle. Trabajan en la ciudad, entre 1905 y 1920, Jorge Inchaurrandieta y Esteban Segundo Adaro (Rodríguez 2011: 29, 201). El primero, con varios cambios de domicilio, pero hacia el 1909 establecido en calle Atacama No 85. Esteban Segundo Adaro tenía estudio en la calle los Carreras $\mathrm{N}^{\circ} 40$, donde según un aviso publicado en el diario El Amigo del País se tomaban los mejores retratos de primera comunión ${ }^{3}$.

En Ovalle y Copiapó el oficio de fotógrafo era reconocido como una actividad social relevante. En el caso de Copiapó, por ejemplo, en el diario El Amigo del País se publicaba, en julio de 1909, los consejos de un fotógrafo para "salir bien" en un retrato: "La que quiera verse reproducida en traje de baile y tenga delgados los brazos y grandes las manos, debe retratarse con el brazo levantado y la mano puesta detrás de la cabeza, con lo cual se consigue un efecto muy bonito y un gusto muy artístico. Si tiene barbilla larga y la cara delgada puede hacer que aparezcan cortas y redondas con solo levantar un poco la barba. Si la cara es gruesa y más redonda de lo que exige la belleza, puede dársele el aspecto de delgada, levantándola y haciéndose retratar con media cabeza en la sombra. Si la nariz es demasiado larga, o demasiado corta, no hay más que levantar ligeramente la cabeza para acortar la nariz y bajarla para alargarla. La boca caída se remedia con una sonrisa; y la grande haciéndose retratar casi de perfil. Si los defectos son muy acentuados es claro que estas reglas son perfectamente inútiles"4.

Otro aspecto relacionado con la fotografía, y que también manifiesta la necesidad por la práctica fotográfica, pero desde el ámbito de la afición, quedó registrado en la prensa del período por la visita que el fotógrafo Calixto Varela realizó a la ciudad de Copiapó. Quien iba a permanecer por una quincena en la ciudad, estuvo tres meses, aproximadamente. Jóvenes, hombres y mujeres, visitaron el taller de Calixto Varela, dueño de la Fotografía Fígaro, quien anunció en el diario El Constitucional que "por pocos días en esta población se instala una Fotografía" que, además de su especialidad en retratos, ofrecía a "los aficionados al arte una lección diaria para poder ejecutar trabajos de fotografía, sin más dirección que su propia iniciativa". Los resultados, al parecer, fueron inmediatos, ya que al finalizar el mes comunicó que en atención al recibimiento otorgado prolongaba su estadía "un mes más, esperando seguir mereciendo la confianza del público en general" y que continuaría dando sus lecciones de fotografía en su taller donde se exhibía el "testimonio de jóvenes y señoritas que han terminado sus estudios en plazo tan corto" 5 .

La práctica fotográfica era una actividad cotidiana. Además, en Ovalle y Copiapó no solo tenían relaciones en estos ámbitos más profesionales y sociales de la fotografía. En la prensa del período, el imaginario fotográfico era utilizado para hacer sátiras, en versos, a las costumbres de la época:
"Quiso Adela, joven pura
Que un fotógrafo famoso
Le enseñara su arte hermoso
Y de la cámara oscura
El secreto misterioso
Pronto con gran perfección
Sacó tarjetas y bustos
Y fue tal su aplicación
Que a los nuevos meses justos
Hizo una reproducción:
Qué tal?"'.

Este poema tiene una versión anterior popularizada en Copiapó en el periódico Fray Lucho. En el caso de Copiapó, Adela se llama Julia y sus clases son con el fraile fotógrafo:

"Quiso Julia, joven pura

Que Frai Agustín, famoso,

Le enseñara su arte hermoso,

I de la cámara oscura

El secreto misterioso

Pronto con gran perfección

Sacó tarjetas y cabezas,

Y tal fue su aplicación

Que perdiendo las chavetas

A los nueves meses justos

Sacó la reproducción

Hola ¡hola! qué pillete, 
Pues salió el domingo siete.

(i dirán que las sotanas

Respetar, saben, hermanas?)"7.

En este contexto de prácticas comerciales, prestigio social y cotidianeidad se enmarca el desarrollo profesional y comercial del fotógrafo Olivares Valdivia. No se encuentra información relativa a sus primeros años de trabajo, pero hacia 1910 José Antonio Olivares Valdivia arrendaba un local para la Fotografía Central en la ciudad de Ovalle. En el periódico La Razón de Ovalle se lee: "El artista fotógrafo Sr. Olivares Valdivia, que tan acabados trabajos ejecuta en su taller situado frente a la Plaza de Armas [...] En su taller fotográfico se exhiben muestras de los trabajos ejecutados según los últimos adelantos del ramo, con gusto y elegancia y a entera satisfacción de los interesados"

Días después de este aviso comercial, Olivares Valdivia cierra el local de Ovalle y viaja a la ciudad de Copiapó donde abrió un nuevo taller, al que también llamó Fotografía Central. El 18 de marzo de 1909 el diario El Progreso de Copiapó informó así la llegada de Olivares Valdivia: "Ha llegado a esta ciudad el señor J. A. Olivares Valdivia y ha establecido su taller denominado Fotografía Central en la calle Atacama al costado de arriba de la casa de don José Santamaría. Hemos visto a la ligera algunas muestras bastante buenas. Tan pronto veamos algunos trabajos de aquí, nos ocuparemos extensamente". Olivares Valdivia arrendó una habitación en una casa de dos pisos en calle Atacama 79 , en lo que se puede llamar la zona comercial y social de la ciudad. Aquí comienza la trayectoria comercial de uno de los estudios fotográficos más antiguo de Copiapó (Figura 1).

\section{La formación de un taller fotográfico en provincia: la Fotografía Central en las ciudades de Ovalle y Copiapó (1909-1918)}

Tanto para la ciudad de Copiapó como para Ovalle la referencia donde se instalaba el fotógrafo era el nombre del propietario del edificio comercial, casa o el hotel. Lentamente las personas de Copiapó y Ovalle se irán acostumbrando al nombre de Fotografía Central. Para lograr esto, usaba la prensa del período con regularidad. Cada uno de sus viajes, y las novedades, las comunicaba en los diarios más conocidos y leídos de la ciudad.

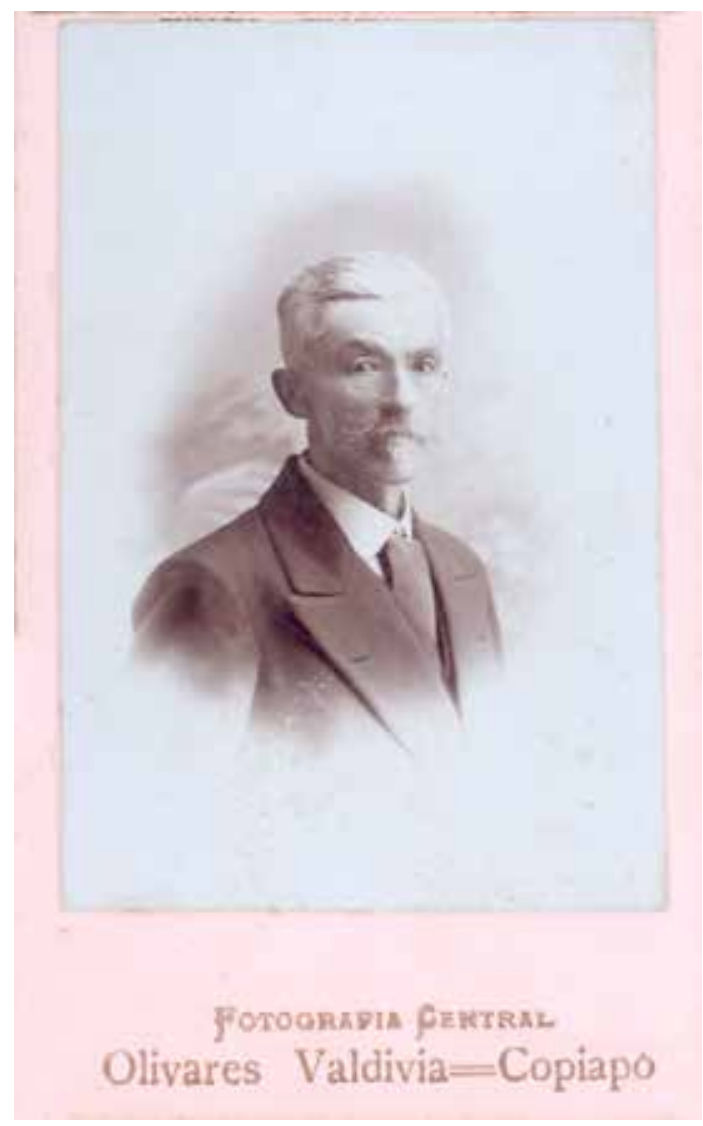

Figura 1. Retrato de Ramón Olguín. Copiapó. 1910. Técnica Colodión. 10.3 x 6.3 cm. Colección Danilo Bruna.

Así, los avisos comerciales se van haciendo cada vez más directos, por ejemplo, en mayo de 1911 publicó el siguiente aviso: "Regresé. J. A. Olivares Valdivia. Fotógrafo-Atacama N ${ }^{\circ} 79$ ".

Pero esta familiaridad, al parecer, está enmarcada en la importancia que va adquiriendo la ciudad de Copiapó. En el diario El Progreso, en su edición de julio de 1910, publica el siguiente aviso: "Tenemos encargo de Sr. J. A. Olivares Valdivia, de avisar a su distinguida clientela y al público en general que teniendo que ausentarse para ir a atender su taller en Ovalle durante la primavera y verano, solo permanecerá dos meses, julio y agosto, tiempo que deben aprovechar para obtener retratos baratos y bien presentados. Durante la ausencia será reemplazado por un ayudante".

A un año de haber instalado la Fotografía Central en Copiapó, Olivares Valdivia anuncia que será "reemplazado por un ayudante". No hay información acerca de quién era su ayudante durante este 
período de nueve meses, pero lo que sí sabemos es que, a partir de agosto de 1911, Olivares Valdivia cuenta con el "competente" señor José Pellegrini, quien se hará cargo de la sucursal de la Fotografía Central en Caldera ${ }^{9}$.

Por esos años no resulta extraño encontrar expresiones de aprobación concernientes a la calidad del trabajo fotográfico de la Fotografía Central. Este reconocimiento y la posibilidad de contar con un ayudante favorecieron a la empresa y el fotógrafo se animó a establecer en Copiapó lo que llamó "El Club de Retratos". Desde "su oficina", como decía un aviso del El Progreso, anunció la organización de este club, que resultó toda una novedad para este diario, ya que le dedicó tres artículos, en junio y julio de 1912, anunciando y explicando los beneficios que disfrutarían los clientes al incorporarse. "La idea del señor Olivares es magnífica", decía el diario, "y merece la mejor atención, pues mediante el sistema de Club todos pueden obtener un hermoso retrato de gran tamaño" 10 .

¿En qué consistía este Club de Retratos? La idea era participar en el sorteo de retratos que se realizarían todos los domingos del mes. Pero para hacerlo más atractivo comercialmente, Olivares Valdivia creo dos Club que funcionaban paralelamente. Una diferencia constaba en que uno era un club donde se sorteaban retratos, mientras que el segundo era el Club de Retratos Grandes o con marco. Otra diferencia entre estos clubes era el valor de la inscripción. Para el primero, la inscripción costaba un peso, para el Club de Retratos Grandes, dos. Ambos clubes se completaban con 50 socios. La condición esencial para participar en el sorteo era el pago anticipado. Los inscritos en el Club de Retratos tenían que pagar durante 30 semanas un peso semanal (7 meses aproximadamente); en el de retratos grandes, dos pesos durante 40 semanas (10 meses). Los sorteos comenzaban cuando estos estuvieran completos. El diario El Progreso, al final de su reseña, afirmaba que "al cabo de 30 semanas han salido 80 socios sorteados con su retrato y los otros 20 reciben también el suyo, de este modo nadie pierde su dinero" 11 .

El primer concurso fue realizado el 7 de julio de 1912. Para esa fecha solo había cerrado el Club $\mathrm{N}^{\circ} 1$ de retratos. El club de retratos grandes esperaba completar la cifra de 50 socios para comenzar los sorteos. Ya para septiembre había comenzado el concurso del club $\mathrm{N}^{\circ} 4$ de retratos y anunciaba que abría el $\mathrm{N}^{\circ} 5$. El club $\mathrm{N}^{\circ} 2$ de retratos grandes aún no completaba el número de socios requeridos.

Los Clubes de Retratos generaron una demanda fotográfica creciente para la Fotografía Central de Olivares Valdivia. Cada semana se informan los resultados del concurso y la apertura de nuevos clubes en Copiapó, Caldera y Ovalle. Para 1916 Fotografía Central avisó en Copiapó la formación del Club número 24 que correspondía a mil doscientos socios. En Ovalle la actividad no era menor: "Si desea usted lo mejor en retratos grandes y además ahorrar dinero y paciencia pase a mi oficina y hágase socio del club $\mathrm{N}^{\circ} 20$. Pagará solo 'un peso semanal"'. Olivares Valdivia en otro aviso dice, "Muchas personas se han acercado a mi oficina con el deseo de ingresar en algún club, por lo que he resuelto dar hoy formación al Club $\mathrm{N}^{\circ} 21$ ". Para el año siguiente quedó completo el club $\mathrm{N}^{\circ} 21$. Hacia 1919 en Copiapó un aviso comercial anunciaba que quedaban los últimos números para el club $\mathrm{N}^{\mathrm{o}} 25$ y sigue en formación el club No $26^{12}$ (Figura 2).

La formación de este Club de Retratos caracteriza aún más la faceta comercial de la Fotografía Central. Olivares Valdivia desarrolló este aspecto, además, con constancia y atención a los adelantos del arte fotográfico, ya que mientras anuncia los

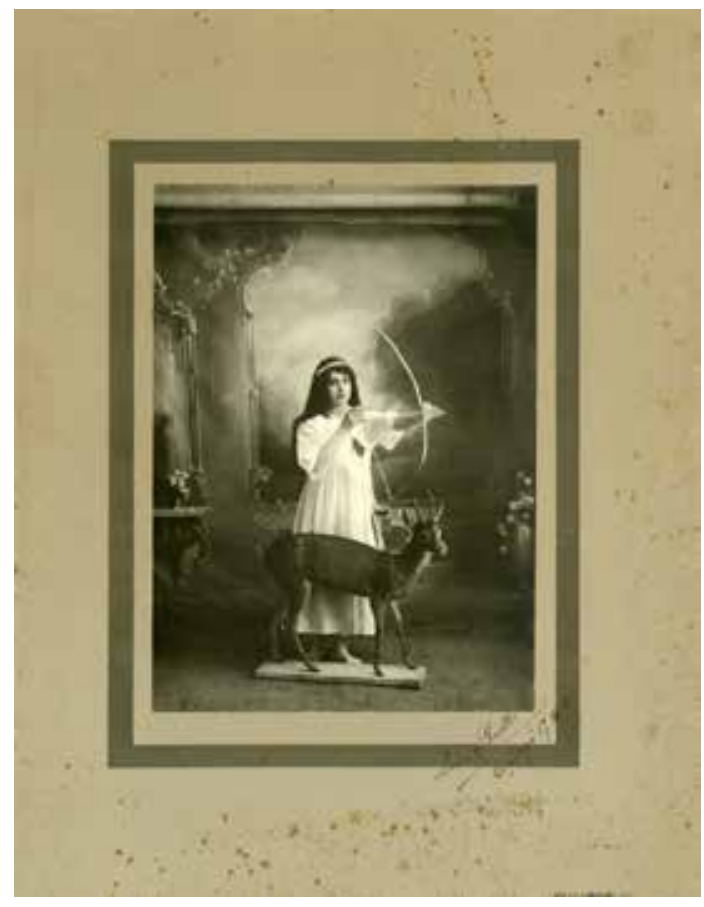

Figura 2. Retrato de Luisa Pratti P. Copiapó. 1916. Técnica gelatina de plata. 27.5 x $21.1 \mathrm{~cm}$. Colección Familia Tornini. 
resultados y formación de un nuevo club también se preocupa de mostrar su habilidad invitando al público a su estudio para que observen sus ampliaciones "a tamaño natural"13.

En otras ocasiones, estas novedades impresionaban a los periodistas que rápidamente se preocupaban de darlas a conocer. En Copiapó, $E l$ Atacameño publicaba la siguiente crónica: "Este inteligente fotógrafo, tan conocido en esta ciudad por sus excelentes trabajos, acaba de regresar del sur y exhibe en la vitrina de su establecimiento una magnífica ampliación que ha llamado justamente la atención del público. Se trata de un pequeño retrato que ha sido ampliado trescientas veces, sin que los rasgos hayan perdido su precisión y limpieza y sin que se note esa vaguedad propia de las ampliaciones. El trabajo exhibido tiene más de un metro y medio de altura y es el de la hijita del señor Diego Aranda, jefe de Estación de esta ciudad. Felicitamos al señor Olivares Valdivia por su hermoso trabajo que manifiesta su constante dedicación a su profesión"14. Olivares Valdivia con un intuitivo olfato comercial aseguraba así su habilidad técnica y la ofrecía a su "distinguida clientela y público en general" en Ovalle y Copiapó como prueba de un trabajo artístico.

\section{La formación de un taller fotográfico en provincia: la competencia comercial en las ciudades de Ovalle y Copiapó (1914-1919)}

“¿Tiene usted su retrato en tamaño grande? ¿Tiene el de sus padres? Esto es algo indispensable pues no tan solo cumpliría usted con un deber, sino que sería el mejor adorno de su casa. He hecho más de mil retratos grandes en las provincias de Coquimbo y Atacama; puedo probar con mis libros esta verdad. MÁS DE MIL. Este número es mi mejor recomendación para ofrecerme en hacer su retrato en tamaño grande, tomándolo directamente o reproduciendo algún retrato pequeño. Olivares Valdivia" 15 .

Una característica que destaca a Olivares Valdivia por sobre otros fotógrafos de este mismo período en la zona del norte chico es la constancia publicitaria $^{16}$. Ya hemos visto cómo durante 1909 a 1916 no dejó de anunciar las oportunidades, novedades e incluso viajes que realizó, pero esta presencia comercial en los diarios alcanzó mayor notoriedad cuando en Copiapó y Ovalle se encontró con otros fotógrafos que utilizaron, como él, los diarios para mostrar sus novedades y ofertas.
El 7 de octubre de 1914 Olivares Valdivia tomó un vapor hacia el sur. En Ovalle, el diario El Tamaya informa que "por cartas que tenemos a la vista, enviadas a particulares, sabemos que pronto vendrá a esta ciudad el conocido fotógrafo Olivares Valdivia, dueño de la Fotografía Central en Copiapó". El fotógrafo, como es ya su costumbre, se encarga de avisar que trae las últimas novedades, esta vez, en papeles "sepia", rebajas en los precios en un cincuenta por ciento y que atiende a domicilio para hacer grupos de familia en sus huertos o jardines sin alterar los precios. Una vez reabierto su estudio en Ovalle, El Tamaya informa que se encuentra disponible al público la Fotografía Central y además que "no tenemos para qué recomendar el trabajo del señor Olivares Valdivia pues es demasiado conocido de nuestra ciudad por haber residido varios años entre nosotros". Con estas referencias, Olivares Valdivia inicia su trabajo en Ovalle, pero con competencia en la ciudad. El fotógrafo Vicente Macayas publica en el mismo diario, bajo el título "Fotografía", el siguiente aviso comercial: "Pongo en conocimiento del público y de mi clientela, que puedo hacer retratos en bromuro, platinos, sepia, carbón, a precios muy reducidos, fuera de toda competencia. Trabajo desde las 9 a.m. a 4 p.m. Todos mis trabajos son garantizados. Taller fotográfico: calle Vicuña Mackena, Plaza de Armas" ${ }^{17}$. La competencia se da en diversos ámbitos: técnicos, comerciales, además de geográficos, ya que Vicente Macayas se ubica en la misma cuadra donde está el estudio de Olivares Valdivia.

La "visita" a Ovalle, que iba a durar 15 días, se extiende hasta el 25 de diciembre del mismo año. Esta queda enmarcada por la aparición de nuevos fotógrafos que utilizan, también, la prensa para convencer y atraer al público. Nuevamente en El Tamaya avisa el "conocido fotógrafo Abraham Cordero, artista fotógrafo", quien prefirió, antes de instalarse en la ciudad, exhibir sus retratos de estudio, grupo y ampliaciones en distintas vitrinas de tiendas de Ovalle ${ }^{18}$.

Los avisos que Olivares Valdivia y Vicente Macayas publicaban en El Tamaya y La Razón, ambos periódicos de la ciudad de Ovalle, destacaban a primera vista por sus variantes tipográficas y porque cubrían más de una columna en las páginas del diario, atrapando con estos recursos la atención del lector ${ }^{19}$. Otras técnicas para seducir al lector se descubren observando la elección de los títulos de los avisos comerciales. Mientras que Olivares 
Valdivia se presentaba como un retratista que traía la última novedad a la ciudad, "Retratos en sepia", se lee en uno de sus avisos comerciales. El fotógrafo Vicente Macayas reducía al mínimo la información: "Fotografía". Otra característica es que sus avisos no estaban ubicados en una sección determinada, como lo eran las secciones de avisos económicos, profesionales o industriales, lo que los hacía más llamativos para el lector.

Para persuadir al público utilizaban el ajustado espacio de sus avisos con argumentos claros y atrayentes. Olivares Valdivia empujaba a sus clientes con la novedad y la moda sin dejar de lado que los retratos estaban a mitad de precio. Vicente Macayas, por otro lado, destacaba su habilidad técnica ya que podía realizar retratos en todas las técnicas fotográficas conocidas $\mathrm{y}$, por supuesto, a precios reducidos fuera de toda competencia.

Olivares Valdivia también encontró en Copiapó, después del período 1909-1915, competencia en los diarios. En 1916 se establece en la ciudad el "artista señor Armando Sills, que en fotografía es una notabilidad", decía el diario La Libertad. Días después, el mismo diario se encarga de informar que además de ser un fotógrafo de primer orden, Sills es un notable pintor y que "por los pueblos que ha recorrido ha dejado bien sentado su fama de artista distinguido" 20 .

Hacia 1916 Armando Sills se instaló en Copiapó en compañía de sus hijos, los cuales tenían cada uno una tarea asignada en el estudio. Las mujeres retocaban los negativos, los hombres lo acompañaban en el laboratorio y el menor tomaba fotografías en la calle con una cámara de cajón. Esta es la "Fotografía Sills i Ca" que se establece en Copiapó. Las comparaciones con la Fotografía Central de Olivares Valdivia son inmediatas. Ambos itineraban por el norte, contaban con ayudantes, aunque en el caso de Olivares Valdivia, solo sabemos de uno, y ambos eran presentados como artistas fotógrafos.

En los diarios de Copiapó la situación era semejante a la de Ovalle: la variedad tipográfica, el traspasar el ancho de la columna y títulos llamativos son característicos de los avisos comerciales que Olivares Valdivia publicaba en los diferentes diarios de la ciudad: "Mil doscientos socios. Este número de socios que han ingresado en los clubes de retratos tamaño natural, es una buena recomendación de la gran aceptación que han tenido. No demore usted en pasar a mi oficina a inscribirse en el club $\mathrm{N}^{\circ} 24$ [...] ya quedan muy pocos números. Olivares Valdivia. Fotografía Central" 21 .

Armando Sills no contaba con tales herramientas comerciales, ni con ese número de clientes, pero sí con la atención de los diarios desde que se instaló en la ciudad. Pero su avanzada comercial en los periódicos comenzó el mismo día, en el mismo diario y en la misma página donde Olivares Valdivia publicó el aviso anterior. Pero mientras Olivares Valdivia desarrollaba argumentos que tenían que ver con la preferencia y oportunidad, Sills destacaba sus cualidades y que sus retratos de estudio eran un artículo exclusivo: "Fotografía Sills i Ca. Recién llegado a esta [...] Ofrece retratos, tamaño natural solo a 30 pesos cada uno. Especialidad en retratos pintados al óleo, acuarela, crayones y al pastel en tonos, colores, precios reducidos. Fotografías tan buenas como las mejores de Europa, hacemos a 6 pesos cincuenta ctvs. docena tamaño visita, a 10 pesos docena tamaño victoria y a 15 pesos tamaño álbum. Retratos rotograbeur de media tinta, última novedad. Aproveche usted única oportunidad. Solo por un mes y medio [...]"22.

Olivares Valdivia se encargaba de avisar cada nuevo adelanto técnico con persistencia -y he ahí una de sus características- durante este período, Armando Sills repetía, con algunas variantes en el orden del texto, las técnicas que podía ofrecer ${ }^{23}$. Pero Armando Sills sacaba provecho a su destacada destreza técnica y estética, que desde un comienzo llamó la atención de los diarios de Copiapó, presentando su trabajo como "comparable a las mejores fotografías de Europa"24.

Durante los años que ambos participaron por "el progreso de la fotografía" dedicaron mucha energía a abastecer la demanda que la ciudad de Copiapó requería. Esta, por los años que les tocó estar juntos (1915-1922 aproximadamente), se concentraba en las fiestas que los alumnos de los diferentes liceos de la ciudad realizaban para la primavera, la primera comunión. Olivares Valdivia durante todo octubre de 1918 da la oportunidad a los estudiantes para que se retraten con sus disfraces. Mientras que Sills además de su condición de fotógrafo-artista, era camarógrafo, y podía llegar a tratos con los organizadores de las fiestas para que le compraran películas de cine con las que iba a filmar las fiestas de ese año ${ }^{25}$.

Por último, Olivares Valdivia también se encargó de alabar y premiar la fidelidad de sus clientes, que es también una práctica común para atraer nuevos 
consumidores. En este caso, les ofrece un regalo por su constante preferencia: "Ciento cuarenta placas. Por término medio, este es el número de placas para un igual número de nuevos clientes que utilizo mensualmente. Esto significa favores del público y que deseo corresponder ofreciendo obsequiarle 'Quinientos Pesos' en forma de sorteo y dividirlo en 9 premios. Cada cliente tendrá un número que guardará para el sorteo. Tres retratos grandes por DOS PESOS OCHENTA CTS. También tendrá derecho al sorteo. Olivares Valdivia" ${ }^{26}$.

\section{Corresponsal gráfico}

Las primeras décadas del siglo XX además de ser años de aprendizaje, formación y expansión del comercio fotográfico en Ovalle y Copiapó, Olivares Valdivia las aprovechó para formar parte de ese largo listado de fotógrafos de provincia que comenzaron a llenar las páginas de las nuevas revistas ilustradas como corresponsales gráficos ${ }^{27}$.

Con las revistas ilustradas del período, sobre todo, Zig-Zag y Sucesos $^{28}$, lo que se impone es visualidad tanto para informar como para comercializar, ya que estas revistas fueron pensadas fundamentalmente para ser vistas (Ossandón y Santa Cruz 2005: 221-222; Rinke 2002: 41-42). En este contexto, los fotógrafos, tanto de estudio como aficionados, encontraron un espacio para fijar los acontecimientos de provincia y ejercer así la función de un productor constante de información encapsulada en una sola imagen o en una serie de ellas (Mraz 1999: 17).

Los "retratos al natural" de Olivares Valdivia tenían presencia en las páginas de los diarios copiapinos y su trabajo de corresponsal le permitía atraer más clientes a su estudio con la promesa de enviar sus fotografías a las revistas.

Es este contexto el que transforma a Olivares Valdivia en corresponsal gráfico de Zig-Zag y Sucesos. Desde 1917 vemos colaboraciones regulares en estas revistas. Bajo el título "de Ovalle" y "de Copiapó" registra, "el matrimonio de Srta. Graciela Aguirre Espoz y el Doctor Gonzalo Castro Toro" o la formación de "La sociedad de los trece" en Copiapó; la ceremonia del " 21 de mayo en Copiapó" ilustrada como una secuencia; o la fotografía de un funeral donde los padres son tomados "Dándole el último adiós", según el título de la revista Sucesos, a su hija fallecida de tifus o las niñas, niños y señoritas de Copiapó que eran estrenadas en sociedad. Inclusos Olivares Valdivia ocupa este espacio para mostrar un fotomontaje, "La Triplicación del notario de Copiapó" 29 .

El trabajo de corresponsal gráfico nos revela una vez más la constante itinerancia que Olivares Valdivia desarrollaba por esos años (1909-1918), a pesar de ser un fotógrafo de estudio reconocido en la provincia de Atacama donde Copiapó, Caldera, Vallenar y Chañaral formaban parte de su círculo de giras comerciales.

El trabajo como corresponsal gráfico dejó un sello en la actividad fotográfica y comercial de Olivares Valdivia que continuó explotando durante la década de los veinte y treinta. Esto tuvo que ver con aprovechar la inmensidad de la vida cotidiana y privada de Copiapó, dejando preciosos registros de momentos sociales y de intimidad. Así fue como comenzó a fotografiar las tertulias, fiestas, las visitas de los presidentes y en ocasiones usó la galería de su taller para mostrar los acontecimientos que conmovían a la ciudad. Así es como en octubre de 1919 el diario El Atacameño informó que "en la fotografía del Sr. Olivares Valdivia se exhiben diversas fotografías tomadas ayer en el funeral de nuestro amigo Oscar Igualt V.”30.

Debido a su experiencia como corresponsal, no es de extrañar que, a fines de la década de los veinte, Olivares Valdivia participara en el primer cambio de importancia, con signo moderno, que la prensa de Copiapó tuvo por esos años, el uso de la imagen para informar (Rinke 2002: 41-42) ${ }^{31}$. Aunque hay antecedentes en los inicios de la década de los veinte, con La Prensa Ilustrada, a fines del año 1928 el diario El Amigo del País comenzó a utilizar la fotografía de forma regular, sobre todo en su magazine de los domingos.

En su edición de 22 de diciembre de ese año $E l$ Amigo del País informa: "A contar desde la edición de mañana, nuestro diario procurará ofrecer a sus lectores fotografías de damas de la localidad, de familias y de niños, como un medio de corresponder al creciente favor del público. Nuestro magazine de mañana llevará la fotografía de una señorita copiapina y todos los domingos se agregará una más al que podremos llamar 'Álbum de este diario'. Hemos hecho al efecto contrato con una empresa editora de Santiago para el suministro regular de clisés. Nuestra edición del lunes, dedicada a Navidad, llevará, además, fotografías de grupos de niños copiapinos. Queremos aprovechar la oportunidad para hacer presente que nuestro reportero gráfico señor 
José Olivares Valdivia, que amablemente secunda los propósitos de este diario, tiene autorización para solicitar de las damas copiapinas su concurso con tal fin y de la gentileza de ellas quedaremos muy agradecidos. A quienes quieran pasar por el estudio fotográfico del señor Olivares Valdivia para el efecto de obtener la copia necesaria para la confección del clisé"32 (Figura 3 y Figura 4).

Desde fines de diciembre de 1928 y durante enero y febrero de 1929, domingo a domingo, el magazine de El Amigo del País contó con la colaboración de las "damas de Copiapó". Estas respondieron durante los primeros meses de manera favorable al reportero gráfico Olivares Valdivia. Sin embargo, durante marzo el diario dejó de publicar el álbum.

Un par de años después, otro diario copiapino, La Mañana, incorporó a sus páginas fotografías y tal como lo hacía El Amigo del País, publicando imágenes de "distinguidas damas copiapinas". La sección "Carnet Social" contó también con imágenes

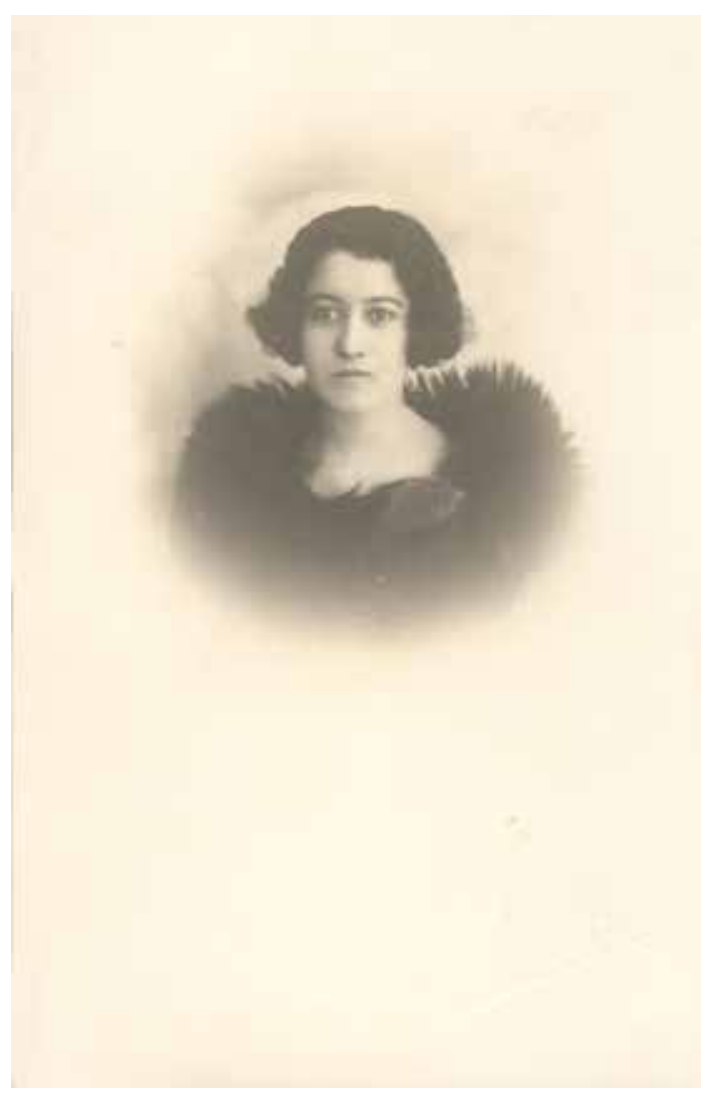

Figura 3. Retrato de mujer no identificada. Copiapó. 1924. Técnica gelatina de plata. 13.8 x $8.6 \mathrm{~cm}$. Colección Danilo Bruna. de Olivares Valdivia, pero además con fotografías de estudios fotográficos de Santiago ${ }^{33}$.

\section{Las décadas de los treinta y cuarenta: agente de la Kodak}

Olivares Valdivia hace más de diez años que vive en Copiapó. En 1926 se casó por el civil con Berta Corona Toledo. Era por esos años, además, un conocido tirador, miembro del club de tiro Libertad, además de director y presidente de la Sociedad de Militares, Civiles y Veteranos del 79, voluntario del cuerpo de bomberos, evangélico, miembro de la sociedad de mutualistas y masón. Desde esos años José Antonio Olivares Valdivia no solo era un fotógrafo, la prensa de Copiapó lo identificaba como un industrial ${ }^{34}$.

En el estudio de Olivares Valdivia trabajaba toda su familia y varios ayudantes que provenían del Liceo de Niñas. Cada uno de sus empleados y empleadas tenía una función definida. Su esposa

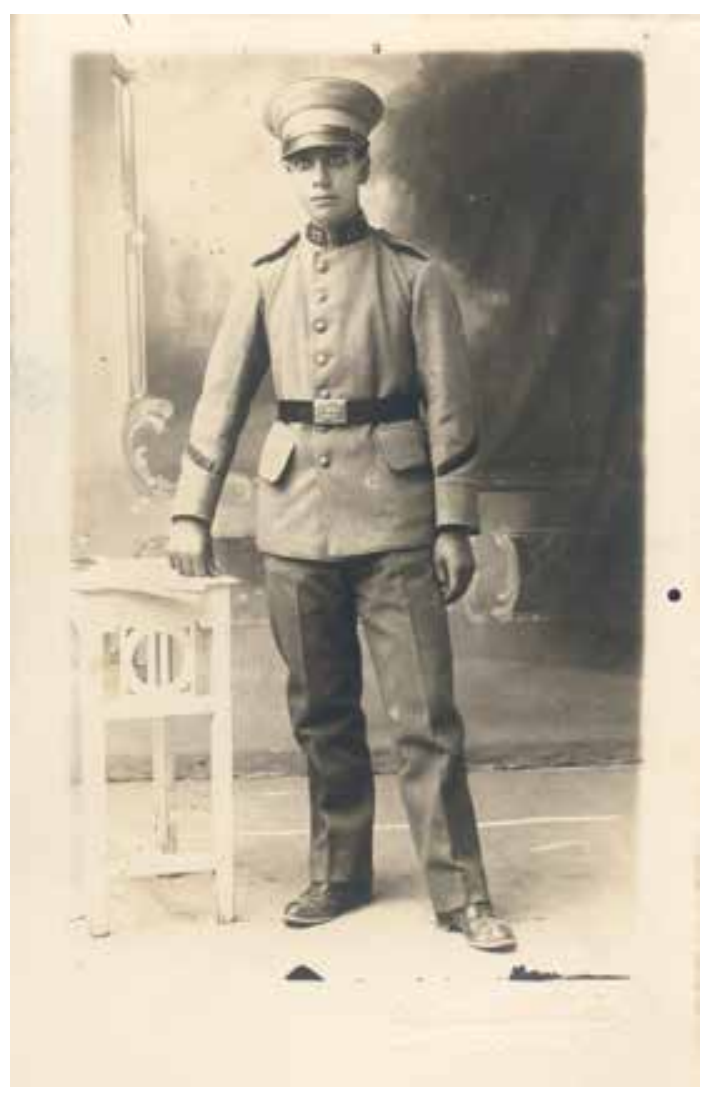

Figura 4. Retrato de Hernando Concha M. Copiapó. 1927. Técnica gelatina de plata. 13.7 x $8.7 \mathrm{~cm}$. Colección Danilo Bruna. 
retocaba y coloreaba las fotografías; su hija menor, Vilna Olivares Corona, junto a Kenny Ortega, trabajaban en el laboratorio y Gioconda Cavalli hacía de asistente del fotógrafo y en ocasiones le tocaba remplazarlo. Por último, por esos años aun trabajaba junto a Olivares Valdivia su antiguo asistente, José Pellegrini.

Para Olivares Valdivia este período era la conclusión natural de años de incesante trabajo que le habían significado levantar una red de relaciones comerciales y sociales. Para muchos en la ciudad, en el estudio fotográfico Olivares Valdivia Copiapó se encontraba "el más notable artista fotógrafo de la región" (Naveas 1978: 7). Y desde hace algunos años, la prensa lo calificaba como un industrial.

Hacia 1928 Olivares Valdivia se convierte en agente autorizado de Kodak en Copiapó, vínculo que amplió su actividad fotográfica y comercial y renovó sus prácticas publicitarias incorporando nuevos diseños a sus avisos publicitarios. Trabajar para la Kodak le permitió, además, contar con toda clase de artículos fotográficos. Esta relación comercial convirtió su estudio en un lugar de reunión frecuente para los fotógrafos aficionados de la ciudad. Fue así como para 1931 realizó un concurso fotográfico, tal vez el primero de su tipo en Copiapó, y en el que tres personas fueron premiadas con artículos Kodak $^{35}$ (Figura 5).

Hacia la década de los treinta, la mujer y la juventud comenzaban a desempeñar un papel preponderante en la prensa de Copiapó. Pero sobre todo la mujer, que cada vez fue adquiriendo más protagonismo en los avisos comerciales de esos años. Si hacia 1909 ella debía salir "bien retratada" de un estudio fotográfico, al concluir la década de los veinte debía sentirse cómoda después de visitar el estudio. Los avisos publicados por Olivares Valdivia por esos años, como agente de la Kodak, permiten inferir esto: "Si no es autográfica no es Kodak. La Vest Poper Kodak [...] pesa 300 gramos, puede llevarla en un bolsillo del chaleco, señorita; puede llevarla en el maletín, es de extremada sencillez y hace fotografía de suma nitidez" ${ }^{36}$.

Pero al igual que los años anteriores, este desarrollo comercial corrió paralelo a la aparición de otros fotógrafos en Copiapó. En 1926 se instaló la casa comercial Hans Frey. La sucursal que se abrió en calle Atacama 561 era "una novedad por su presentación artística, por la exhibición inteligente de los artículos que en venta allí se ofrecen”, decía

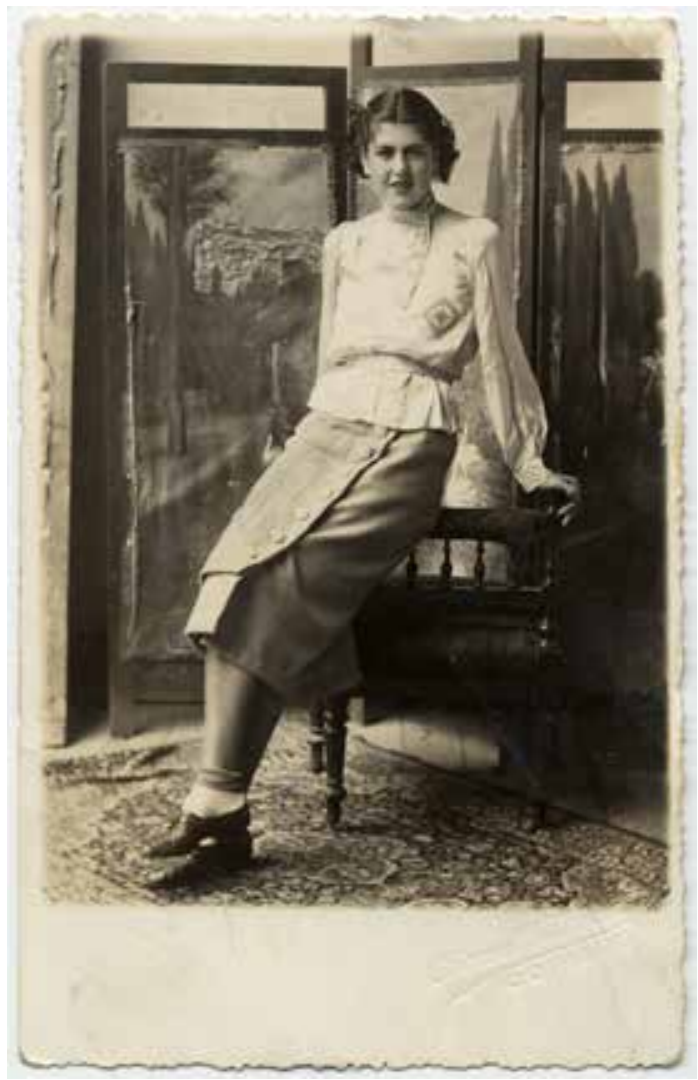

Figura 5. Retrato de Sara Culla Venegas. Copiapó. 1937. Técnica gelatina de plata. 13.7 x 8.7 cm. Colección Ibar González.

El Atacameño. La casa Hans Frey era la casa fotográfica más antigua del país y contaba con diversos establecimientos ${ }^{37}$

Junto a la presencia comercial de la Casa Hans Frey en Copiapó, otros fotógrafos aparecen o vuelven a la ciudad. Alberto Tello, por ejemplo, quien es especialista en "retratos, bustos y grupos familiares con buen material moderno" ${ }^{38}$. También por esos años estaba plenamente activo Esteban Segundo Adaro, cuyo trabajo también era reproducido en los diarios de Copiapó y la revista Zig-Zag.

Mientras esto ocurría, Olivares Valdivia no abandonó su trabajo en el estudio, pero adaptó su actividad, sobre todo para ampliar el número de clientes: "Olivares Valdivia. Ofrece a su distinguida clientela, por una corta temporada, la oportunidad de obtener un retrato grande (ampliación al bromuro $40 \times 50 \mathrm{~cm}$ ) de valor de $\$ 100$, por la mitad de su precio, o sea, $\$ 50$, y, además, facilidades de pago. Visite usted, vea muestras en su oficina, y seguramente querrá aprovechar esta 
única ocasión [...] Del interior remitir originales a casilla $203 " 39$. Las nuevas prácticas de compra a cuotas comenzaron a facilitar el acceso a una mayor parte de la población para obtener un retrato grande, familiar o de grupo.

Estos avisos también nos muestran que el trabajo fotográfico más importante seguía siendo el retrato de estudio. Que esta práctica estaba profundamente arraigada en la cultura de autorrepresentación de los copiapinos, sobre todo por la persistencia en ofrecer "el retrato grande" ( 40 x $50 \mathrm{~cm})$. Por último, esto se puede ver en la presencia que tiene el retrato en la prensa de Copiapó que, como ya hemos reseñado, comienza publicar series de estos por medio de "El Álbum del Amigo del País" y el "Carnet Social" del diario La Mañana (Figura 6).

Hacia 1940 el estudio de José Antonio Olivares Valdivia presentaba una tradición fotográfica de más de 30 años. Había formado fotógrafos y de a poco delegaba su labor en su hija menor y en sus ayudantes. Vilna Olivares, muy joven, comenzó a hacerse cargo del estudio, repitiendo de alguna manera la historia de su padre. En 1948 Olivares

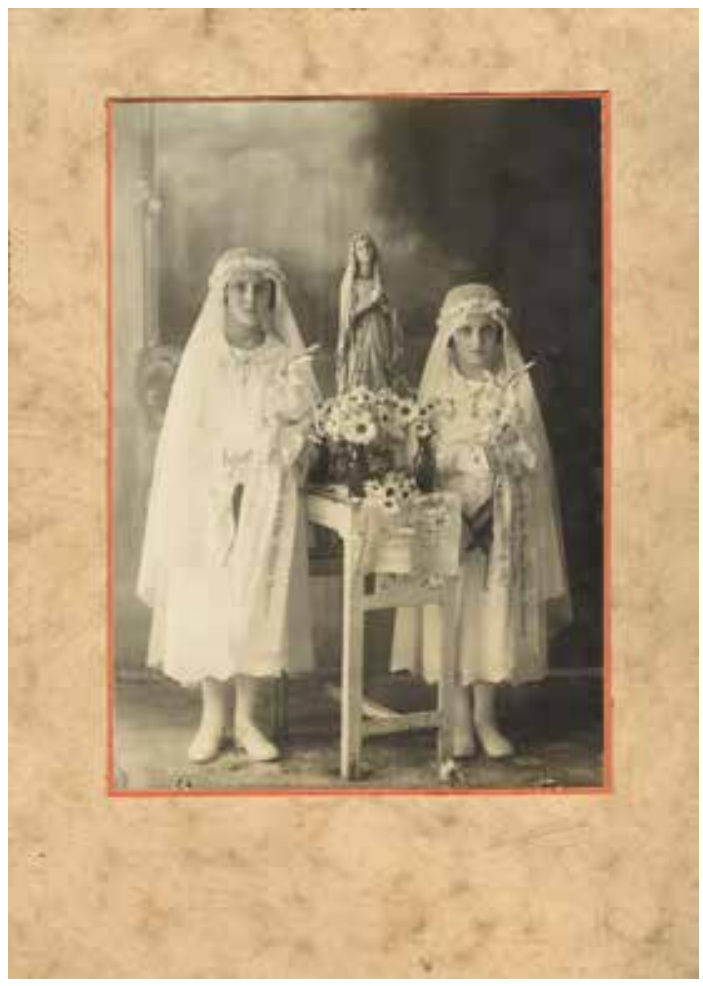

Figura 6. Retrato de primera comunión de Pilar y Nieves Orruño. Copiapó. 1933. Técnica gelatina de plata. 24.9 x 17.5 cm. Colección Eliana Herrero.
Valdivia abandonó el trabajo de fotógrafo; pasaba la mayor parte del tiempo en su casa enfermo. El 10 de noviembre de 1948, a los 64 años de edad, fallece de una insuficiencia cardiaca.

Cuatro años después sobrevino una desgracia. El 28 de agosto de 1952 un incendio destruyó una cuadra completa de la calle Atacama. Una a una se incendiaron las casas y edificios que formaban parte de esta tradicional calle. Primero el Club Radical, luego los inmuebles vecinos, entre los que se encontraba la Fotografía Olivares Valdivia. El fuego que se inició pasada la 1 de la madrugada fue controlado recién siete horas después. El diario concluyó la nota informando que las pérdidas son cuantiosas en la "Foto Olivares Valdivia, Atacama 454, de la señora Berta, viuda de Olivares". Berta Corona y Vilna Olivares, esposa e hija del fotógrafo, fueron auxiliadas por familiares. Del estudio no lograron rescatar nada. Al tiempo, la familia decidió abandonar la ciudad y se trasladó a la capital. El estudio no volvió a abrir sus puertas ${ }^{40}$.

\section{A modo de conclusión La Fotografía Central: 40 años de trabajo en Copiapó}

Entre 1909 y 1922 el fotógrafo José Antonio Olivares Valdivia trabajó por ampliar su negocio y por lograr una mejor situación económica. La evolución la notamos, entre otras cosas, en los cambios de domicilio que experimentó su estudio fotográfico, el que primero se instaló en una habitación arrendada en un segundo piso, hasta ubicarse en su dirección definitiva, Atacama 454, donde estableció su estudio fotográfico que fue además sala de exposición, oficina de noticias locales y agencia de productos fotográficos Kodak.

Durante esos años el nombre de "Fotografía Central", Ovalle o Copiapó, dependiendo donde estuviera, cambió y muy pronto comenzó a ganar una identidad local: "Olivares Valdivia Copiapó" pasó a ser la marca comercial y sello distintivo del fotógrafo. Sus apellidos fueron en ese momento sinónimo de fotografía, buena atención, gusto, calidad, esmero, trabajo y arte.

Con su actividad y movimiento por las ciudades del norte, Ovalle, Copiapó, Caldera, Chañaral, llevó la modernidad que quedó plasmada en cientos de avisos comerciales que publicó en los diarios de esas ciudades. Al examinarlos más en detalle, encontramos una forma de describir el desarrollo 
y formación de un fotógrafo y acercarnos a la instrucción de otros fotógrafos, hombres y mujeres, que trabajaron o pasaron por su estudio.

En Copiapó, el desarrollo y consolidación del estudio fotográfico se completó gracias a la función que Olivares Valdivia cumplió en las revistas ilustradas Sucesos y Zig-Zag, donde mensualmente colaboró con imágenes llenas de información local como accidentes, terremotos, nacimientos, matrimonios, muertes, inauguraciones y ceremonias. Esta función marcó en los años siguientes su trabajo fotográfico y nos legó un testimonio sobre la ciudad y su realidad cultural y social, pero impregnado de familiaridad.

\section{Referencias Citadas}

Bergot, S.

2008 Los Sills. Una Familia Detrás de las Cámara. Centro Nacional del Patrimonio Fotográfico, Santiago.

Dussaillant, J.

1993 Breve historia de los avisos publicitarios en los principales periódicos chilenos 1850-1920. Tesis para optar al grado de Licenciado en Historia, Instituto de Historia, Pontificia Universidad Católica de Chile, Santiago.

Navarrete, J.

2002 Las buenas maneras. Fotografía y sujeto burgués en América Latina (siglo XIX). Aisthesis 35: 11-15.

Ossandón, C. y Santa Cruz, E.

2005 Estallido de las Formas: Chile en los albores de la "cultura de masas". LOM-ARCIS, Santiago.

Mraz, J.

1999 Nacho López y el fotoperiodismo mexicano en los años cincuenta, Océano. México. 1999.
Naveas, E.

1978 Principales lugares históricos de Copiapó. Contribuciones Históricas $\mathrm{N}^{\mathrm{o}} 1$, Copiapó.

Rinke, $\mathrm{S}$.

2002 Cultura de masas: reforma y nacionalismo en Chile 1910-1931. Dibam, Santiago.

Rodríguez, $\mathrm{H}$.

2001 Historia de la fotografía en Chile. Fotógrafos en Chile durante el siglo XIX. Centro Nacional del Patrimonio Fotográfico, Santiago.

Rodríguez, $\mathrm{H}$.

2011 Historia de la fotografía. Fotógrafos en Chile 1900-1950. Centro Nacional del Patrimonio Fotográfico, Santiago. Soffia, A.

2003 Lea el mundo cada semana. Prácticas de lectura en Chile 1930-1945. Ediciones Universitaria de Valparaíso. Valparaíso.

\section{Notas}

1 Entrevista a Vilna Olivares (hija menor del fotógrafo), Santiago, 19 de octubre 2003. Sobre sus años de aprendizaje y formación como fotógrafo su hija no tiene antecedentes, como se consultó algún libro o aprendió en los talleres de otro fotógrafo en la ciudad de Ovalle. Sobre el aprendizaje fotográfico durante el siglo XIX se puede consultar la obra de Rodríguez 2001.

2 El Tamaya (Ovalle), 23 de marzo de 1892.

3 El Amigo del País (Copiapó), 7 de agosto 1909.

4 El Amigo del País (Copiapó), 28 de julio 1909. Para contextualizar esta información de prensa ver Navarrete 2002: $10-15$.

5 El Constitucional (Copiapó), 9 de enero 1897.

6 El Libertario (Ovalle), 9 de junio 1907.

7 El Frai Lucho (Copiapó), 15 de enero de 1905.

8 La Constitución (Ovalle), 27 de enero de 1910.

9 El Progreso (Copiapó), 26 de agosto 1911. Hacia 1909, José Pellegrini figura como el encargado de un almacén en Caldera con surtido general en abarrotes, artículos de tienda, paquetería y comisiones comerciales. A primera vista, un hombre alejado de la actividad fotográfica. Lo cierto es que nada sabemos acerca de su formación o cercanía con la fotografía. Suponemos que Olivares Valdivia lo conoció en este puerto cuando a fines de abril de 1911 se detuvo un mes para tomar retratos, tiempo donde probablemente se familiarizó con él, lo tomó como ayudante, formándolo en su taller y dejándolo, cuatro meses después, a cargo de la nueva sucursal en Caldera. Sobre el estudio en Caldera ver El Progreso (Copiapó), 22 de abril de 1911. Sobre José Pellegrini ver El Progreso (Copiapó), 2 de marzo de 1909.

10 El Progreso (Copiapó), 18 de junio de 1912. El Progreso (Copiapó), 6 de julio de 1912. Antecedentes relativos a esta idea u otras parecidas no hemos encontrado en Copiapó, pero sí en Ovalle donde Juan Jiles anunciaba la creación del "Club de Trajes", La Constitución (Ovalle), 22 de noviembre de 1903. La información que el diario entrega del club es la siguiente: "Prospecto y condiciones. Bases y condiciones del club. El número de socios será 75 . Cada socio pagará una cuota semanal de 2 pesos. El número de semanas que habrá de pagar será de 32; de modo que un terno no puede costar más de 64 pesos ni menos de 2 . Los últimos 43 socios tendrán opción además del correspondiente terno o un nuevo premio cada uno; se sortearán los 43, siendo todos premiados. Los objetos serán los útiles i especies que paso a enumerar. Sombreros finos de paja, calcetines, pañuelos de mano, escobillas para ropa, guantes finos de punto, corbatas, medias para señoras, cortes de chalecos, cuellos, puños, cortes de piqué para blusas, etc. etc. Los casimires que emplearé para los trajes, es decir, 
vestón, pantalón i chaleco, serán todos de valor de 55 pesos, materiales finos i trabajo esmerado. Se avisa al público que habiéndose completado el primer club de trajes, se ha dado principio a la formación del $2^{\circ}$, en el cual figura ya un buen número de socios i queda en espera de las gratas órdenes de mis favorecedores para que se apresuren a tomar los números vacantes".

11 El Progreso (Copiapó), 18 de junio de 1912.

12 La Razón (Ovalle), 21 de agosto de 1915; La Libertad (Copiapó), 7 de junio de 1916; La Razón (Ovalle), 2 de noviembre de 1915; El Atacameño (Copiapó), 12 de septiembre de 1918; El Atacameño (Copiapó), 10 de febrero de 1919.

13 La Razón (Ovalle), 7 de octubre de 1915; El Norte (Copiapó), 31 de octubre de 1916; El Atacameño (Copiapó), 11 de mayo de 1918, Olivares Valdivia; La Libertad (Copiapó), 7 de junio de 1916: "Mil doscientos socios. Este número de socios que han ingresado en los clubes de retratos tamaño natural, es una buena recomendación de la gran aceptación que han tenido. No demoré ud. en pasar a mi oficina a inscribirse (...)". La Razón (Ovalle), 21 de agosto de 1915, Retratos Grandes, “¿Desea ud. evitar una demora a veces muy larga en encargar sus retratos al extranjero, cuyos artistas le quedan muy lejos para sus reclamos? (...) Pase a mi oficina y hágase socio del club $\mathrm{N}^{\circ} 20$. Pagará solo 'un peso semanal'. Olivares Valdivia. Fotografía Central. Plaza de Armas"; El Atacameño (Copiapó), 6 de junio de 1915, Retratos tamaño natural: "Retratos tamaño natural. Si desea ud. un retrato tamaño natural suyo o de alguna persona de su familia ya sea tomado o reproducido de otro retrato, le conviene tomar un número en el Club N 22, pagará ud. solamente un peso semanal y le haré ese retrato en bromuro, negro carbón o si lo prefiere ud. virado en colores. Para más detalles verse en mi establecimiento. Olivares Valdivia".

14 El Atacameño (Copiapó), 11 de mayo de 1918.

15 El Amigo del País (Copiapó), 10 de mayo de 1918.

16 Sobre este concepto Jacqueline Dussaillant indica que para el período 1850-1920 un aspecto relevante en la publicidad en la prensa de la época era la "constancia" en la publicidad de los avisos. Para algunos esto hacía realidad hacerse rico por medio de los anuncios. Esta constancia publicitaria indicaba el "saber hacer publicidad". Esto significada, además de la característica antes mencionada, el tener bien pensada y diseñada la publicidad. Rasgos que caracterizan este aspecto son diversidad de tamaño de las tipografías, lugar del aviso en la página, claridad, originalidad, simpatía. Ver Dussaillant 1993.

17 El Atacameño (Copiapó), 7 de octubre de 1914. El Tamaya (Ovalle), 7 de octubre de 1914. El Tamaya (Ovalle), 16 de octubre de 1914; El Tamaya (Ovalle), 17 de octubre de 1914. El Tamaya (Ovalle), 21 de octubre de 1914. Sobre este fotógrafo no hemos encontrado ninguna referencia. Suponemos que estaba instalado en Ovalle desde 1914 y al parecer solo estuvo un año en la ciudad.

18 El Tamaya (Ovalle), 17 de octubre; 8 de diciembre de 1914.

19 En El Tamaya (Ovalle), 17 de octubre de 1914; El Tamaya (Ovalle), 21 de octubre de 1914; La Razón (Ovalle), 21 de agosto de 1915; La razón (Ovalle), 2 de noviembre de 1915.
20 La Libertad (Copiapó), 25 de marzo de 1916; La Libertad (Copiapó), 29 de marzo de 1916. Sobre el fotógrafo Armando Sills, y su familia, se puede consultar Bergot 2008.

$21 \quad$ La Libertad (Copiapó), 7 de junio de 1916.

$22 \quad$ La Libertad (Copiapó), 7 de junio de 1916.

23 El Amigo del País (Copiapó), 1 de junio de 1918, "Con toda seguridad hará una jira a Caldera donde permanecerá pocos días antes de seguir al norte. Hace reproducciones y engrandecimientos desde 5 pesos arriba; fotografías en miniatura esmaltadas, de color natural, para prendedores y colleras, colgantes para caderas y fotominiaturitas esmaltadas en relojes de oro, plata i nickel. Retratos al óleo y acuarela en color sepia, azul, perla y verde. VEAN LOS MUESTRARIOS. Precios de retratos. Óvalo tamaño midget a \$ 4.00 la media docena. Tamaño más grande a 8,12 i 18 pesos la media docena. Grupo de familia hasta cinco personas a $\$ 25.00$ en elegante tarjeta. Retratos al platino y rotogrivure (sic) colores sepia, verde, azul, perla y calamar, se hace a precio convencional. Estos trabajos son los de última creación en Europa". En El Atacameño (Copiapó), 30 de mayo 1918, pública un aviso similar. "Trabajo serio comparable a las mejores fotografías de Europa, podrá uds. hacerse en la fotografía 'Sills' con la seguridad de quedar altamente satisfechos. Retratos al óleo, acuarela y crayones se hacen con toda perfección y a precios equitativos. Se le devolverá el dinero si ud. no quedara conforme con los trabajos que se confeccionan en esta fotografía".

24 Es difícil dimensionar el papel que la fotografía Sills tuvo en la ciudad de Copiapó, toda vez que como llegó a Copiapó la dejó, y que su archivo, hasta hoy, solo consta de un centenar de fotografías en poder de algunos nietos. Esta colección forma parte del patrimonio de la familia Sills de Copiapó y del Centro Nacional del Patrimonio Fotográfico de la Universidad Diego Portales (Bergot 2008).

25 Estas vistas de la fiesta iban a ser exhibidas en el biógrafo de la ciudad, que era el teatro municipal. Imágenes como estas eran alentadas y aprobadas por cierto sector educado de la sociedad, ya que tenía un carácter documental, veraz y educativo irremplazable. Benjamín Figueroa, director del diario El Norte, escribió una larga crónica, motivada por la nueva industria nacional, La Chile Films, donde afirmaba que esta tiene una importancia capital, ya que "hasta la fecha el cinematógrafo nos ha dado a conocer las bellezas de los paisajes europeos (por lo tanto) preciso es que principiemos a conocer nuestra propia casa". El Norte (Copiapó), 22 de febrero de 1917.

26 El Atacameño (Copiapó), 6 de marzo de 1919.

27 En el caso de Copiapó durante los años 1909-1932 hemos encontrado también como corresponsales gráficos a Guillermo Dunstan, José Pellegrini Giovanetti, Esteban Segundo Adaro y Armando Sills, todos colaborando con las Revistas Sucesos, Zig-Zag, y el diario El Atacameño, en Copiapó.

28 Sobre la revista Sucesos y Zig-Zag ver Soffia 2003 y Ossandón et al. 2005.

29 Sucesos (Valparaíso), 17 de mayo 1917; 31 de mayo de 1917; 6 de diciembre 1917; 13 de diciembre de 1917; 27 de diciembre de 1917; 3 de enero de 1918; 24 de octubre de 1918; 7 de noviembre de 1918; 5 de diciembre de 1918. 30 El Atacameño (Copiapó), 24 de octubre de 1919. 
31 Páginas ilustradas se encontrado en los siguientes diarios de Copiapó: El Progreso (Copiapó), 28 de junio de 1910; El Amigo del País (Copiapó), 2 de mayo de 1916; El Atacameño (Copiapó), 23 de junio de 1917; El Amigo del País (Copiapó), 16 de enero de 1919; El Atacameño (Copiapó), 26 de abril de 1922.

32 El Amigo del País (Copiapó), 22 de diciembre de 1928.

33 La Mañana (Copiapó), marzo, abril de 1935.
34 El Atacameño (Copiapó), 22 de agosto de 1934.

35 El Amigo del País (Copiapó), 26 de diciembre de 1931.

36 El Amigo del País (Copiapó), 9 de diciembre de 1928.

37 El Atacameño (Copiapó), 1 de junio de 1926, "La Casa Hans Frey abre sus puertas en esta ciudad".

38 El Atacameño (Copiapó), 22 de octubre de 1926.

39 El Atacameño (Copiapó), 30 de julio de 1927.

40 El Amigo del País (Copiapó), 28 de agosto de 1952. 
